Editorial

\title{
Expediting a Manuscript: Need of the Hour
}

\author{
Shyamkumar N. Keshava ${ }^{1}$ Sanjeeva Kalva² \\ ${ }^{1}$ Department of Interventional Radiology, Division of Clinical \\ Radiology, Christian Medical College, Vellore, Tamil Nadu, India \\ ${ }^{2}$ Division of Interventional Radiology, Department of Radiology, \\ Massachusetts General Hospital, Boston, Massachusetts, \\ United States
}

J Clin Interv Radiol ISVIR:2020;4:133-134

During the current ongoing coronavirus disease 2019 (COVID-19) pandemic, publishing relevant manuscripts expeditiously is a felt need. A short turnaround time for rapid dissemination of scientific data is of paramount importance. Many journals ensured this task with added resources and have been very successful. ${ }^{1}$ This process has been called by different names-rapid publication, accelerated publication, expediting, fast-tracking, etc. Despite various names and overall understanding of the process, there are no strict definitions or guidelines for rapid publishing. When the duration from submission to publication is reduced to less than half of the routine turnaround time by conscious and deliberate efforts, such terminologies could be used. Journals with an online presence can publish the manuscript as "online first" articles for quick access to the readers. Since these preprint versions are displayed with Digital Object Identifiers (DOIs), subsequent citations are possible even without a formal attachment to a journal issue. Of note, many journals, for the benefit of the public and scientific community, have provided free, open access to all COVID-related publications.

The editorial board of JCIR and Thieme publishers considered it a high priority to publish COVID-19 related manuscripts expeditiously. Given the age of the journal, this was the first time our team approached the rapid publication process. Everyone in the team agreed on the responsibility and importance of making the information available to our readers as fast as possible. Additional steps were considered and implemented swiftly. The review process of the manuscripts was expedited by requesting rapid turnaround (within 2 days) from our distinguished reviewers. The manuscripts were assigned to twice the routine number of reviewers at the beginning to avoid delays in peer review of the manuscripts due to the unavailability of the reviewers. Authors were made aware of the process through e-mails and phone messages to provide quick feedback on the stage of the review process and the journal's expectation of rapid revision to the manuscripts based on the reviewers' comments. The publisher team worked tirelessly to bring these manuscripts for rapid production and offer it as "eFirst" articles.,

However, we should be cautious when we expedite the publication process. ${ }^{4}$ A good intention is not all that counts. If one decides to facilitate a rapid publication, one should run an extra mile and not bypass the mandatory peer review process. The quality of the manuscript should not be compromised. If the published information is found to be erroneous by subsequent detailed research, the authors and the journal have the moral obligation to publish an erratum or even withdraw the published manuscript. The facility of rapid publications should not be misused by anyone. We should also remember that the results of some of the key medical publications are passed on to the community by the newspapers.

A quick dissemination of scientific knowledge is a contribution to the society overall. The purpose should be clear. It has a significant impact on the practice of medicine and quality of care delivered to our patients. It would be appropriate to develop and provide specific "author guidelines" and delineate the process for expedited publishing. Speed should be achieved by extra efforts and not by taking short cuts to the process. Finally, fast-tracking of a manuscript is only appropriate when it has a substantial impact on patient care and should not be used as a routine process or for personal gains.
Address for correspondence Shyamkumar N. Keshava, DMRD, DNB, FRCR, FRANZCR, Department of Interventional Radiology, Division of Clinical Radiology, Christian Medical College, Ida Scudder Road, Vellore, Tamil Nadu 632004, India (e-mail: shyamkumar.n.keshava@gmail. com).
DOI https://doi.org/ 10.1055/s-0040-1722106 ISSN 2457-0214.

\footnotetext{
(C) 2020. Indian Society of Vascular and Interventional Radiology.

This is an open access article published by Thieme under the terms of the Creative Commons Attribution-NonDerivative-NonCommercial-License, permitting copying and reproduction so long as the original work is given appropriate credit. Contents may not be used for commercial purposes, or adapted, remixed, transformed or built upon. (https://creativecommons.org/licenses/by-nc-nd/4.0/).

Thieme Medical and Scientific Publishers Pvt. Ltd. A-12, 2nd Floor, Sector 2, Noida-201301 UP, India
} 


\section{Conflict of Interest}

None declared.

\section{References}

1 Chandy PE, Nasir MU, Srinivasan S. Klass D, Nicolaou S, B Babu S. Interventional radiology and COVID-19: evidencebased measures to limit transmission. Diagn Interv Radiol 2020;26(3):236-240

2 Babu AA, Padmanabhan A, Khera PS, Sonwalkar H. Better safe than sorry: interventional radiology should be prepared for the coronavirus disease 2019 pandemic. J Clin Interv Radiol ISVIR 2020;4:38-41
3 Roy-Choudhury SH, Warawdekar G, Could interventional radiological therapies offer a safer alternative as we emerge from COVID-19 pandemic? J Clin Interv Radiol2020 (e-pub ahead of print). doi: $10.1055 / \mathrm{s}-0040-1714312$

4 King A. Fast news or fake news?: The advantages and the pitfalls of rapid publication through pre-print servers during a pandemic. EMBO Rep 2020;21(6):e50817 